\title{
Trends and perspectives of space-borne SAR remote sensing for archaeological landscape and cultural heritage applications
}

1 Deodato TAPETE ${ }^{\mathrm{a},}{ }^{*}$, FrAnCESCA Cigna $^{\mathrm{a}}$

2

${ }^{a}$ British Geological Survey, Natural Environment Research Council, Nicker Hill, Keyworth, NG12 $5 \mathrm{GG}, \mathrm{UK}$;

*Corresponding author. Telephone: +44 (0) 1159363537

E-mail address: deodato@bgs.ac.uk

3

4 Abstract

5 This paper provides an overview of the opportunities that image analysts, archaeologists and conservation

6 scientists currently have of using space-borne Synthetic Aperture Radar (SAR) imagery for prospection of

7 cultural landscapes and investigation of environmental, land surface and anthropogenic processes that can alter

8 the condition of heritage assets. The benefits of the recent developments in SAR satellite sensors towards higher

9 resolution (up to less than 1 metre) and shorter revisiting times (up to a few days) are discussed in relation to established techniques using the two key SAR parameters - amplitude and phase. Selected case studies from

11 Middle East to South America illustrate how SAR can be effectively used to detect subtle archaeological 12 features in modern landscapes, monitor historic sites and assess damage in areas of conflict. These examples 13 form the basis to highlight the current trends in archaeological remote sensing based on space-borne SAR data 14 in the current era of the European Space Agency's Sentinel-1 constellation and on-demand high resolution space 15 missions.

16 KEYWORDS

17 Radar remote sensing; SAR; amplitude; phase; change detection; archaeological remote sensing; damage 18 assessment; cultural heritage; Syria; Nazca 


\section{INTRODUCTION}

This paper aims to provide an overview on the use of Synthetic Aperture Radar (SAR) images acquired from space for purposes of archaeological landscape studies and cultural heritage applications, in recognition of the increasing role that this branch of remote sensing is playing in the field of archaeological science.

Recent reviews have been published to illustrate the basic principles that make SAR suitable for archaeological prospection (Lasaponara and Masini, 2013; Chen et al., 2015a) and showcase some successful achievements with high resolution SAR sensors (Chen et al., 2015b). But an assessment of the current trends in SAR archaeological remote sensing has not been carried out yet, alongside a review of the existing opportunities offered by the recent technological developments.

It is to fill this gap that in this paper we review the three key factors - data, processing methods and application types - that at present favour the exploitation of this space technology to complement well-established techniques of aerial photography, optical remote sensing and generation of digital elevation models (DEMs).

\section{BACKGROUND AND GROWING IMPACT}

From an historical perspective, the earliest use of SAR to study paleo-landscapes dates back to the 1980s with investigations in both tropical and subtropical territories (Adams et al., 1981) and arid environments (Elachi et al., 1984). Since then, several studies revealed hidden features and paleo-landscapes, by exploiting the peculiar penetration capability of the radar signal (El-Baz, 1998; Lira et al., 2005; Wiseman and El-Baz, 2007; Evans et al., 2007; Moore et al., 2007) at the different microwave bands of acquisition, i.e. $L$ 1-2 GHz, 15-30 cm; $C$ 4-8 $\mathrm{GHz}, 3.75-7.5 \mathrm{~cm} ; X 8-12.5 \mathrm{GHz}, 2.5-3.75 \mathrm{~cm}$, and proving that better performance is usually obtained at longer wavelengths (L- > X-band) and in drier and fine-grained soils.

A proof of evidence of the growing scientific relevance that SAR is assuming in this field is gathered in Figure 1. Using a similar approach to that described by Agapiou and Lisandrou (2015), a Scopus engine search of the keywords 'radar', 'remote sensing', 'archaeology', 'cultural heritage' and 'polarimetry', highlights that there has been a significant increase of indexed peer-reviewed publications focussed on the use of SAR for archaeological science in the last 30 years (series "Total" in Figure 1). A steady increase is observed until 2011, while the publication boost occurred in 2013 with the publication of a dedicated special issue on Archaeological Prospection. Although this search is not exhaustive (and does not pretend to be so), it provides an interesting 
and objective bibliometric. The analysis of authors' affiliations also reveals that one third of the total number of these publications has involved research teams including archaeologists (series "Archaeology" in Figure 1), and confirms that teamwork between archaeologists and remote sensing experts is increasing since the late 1990s.

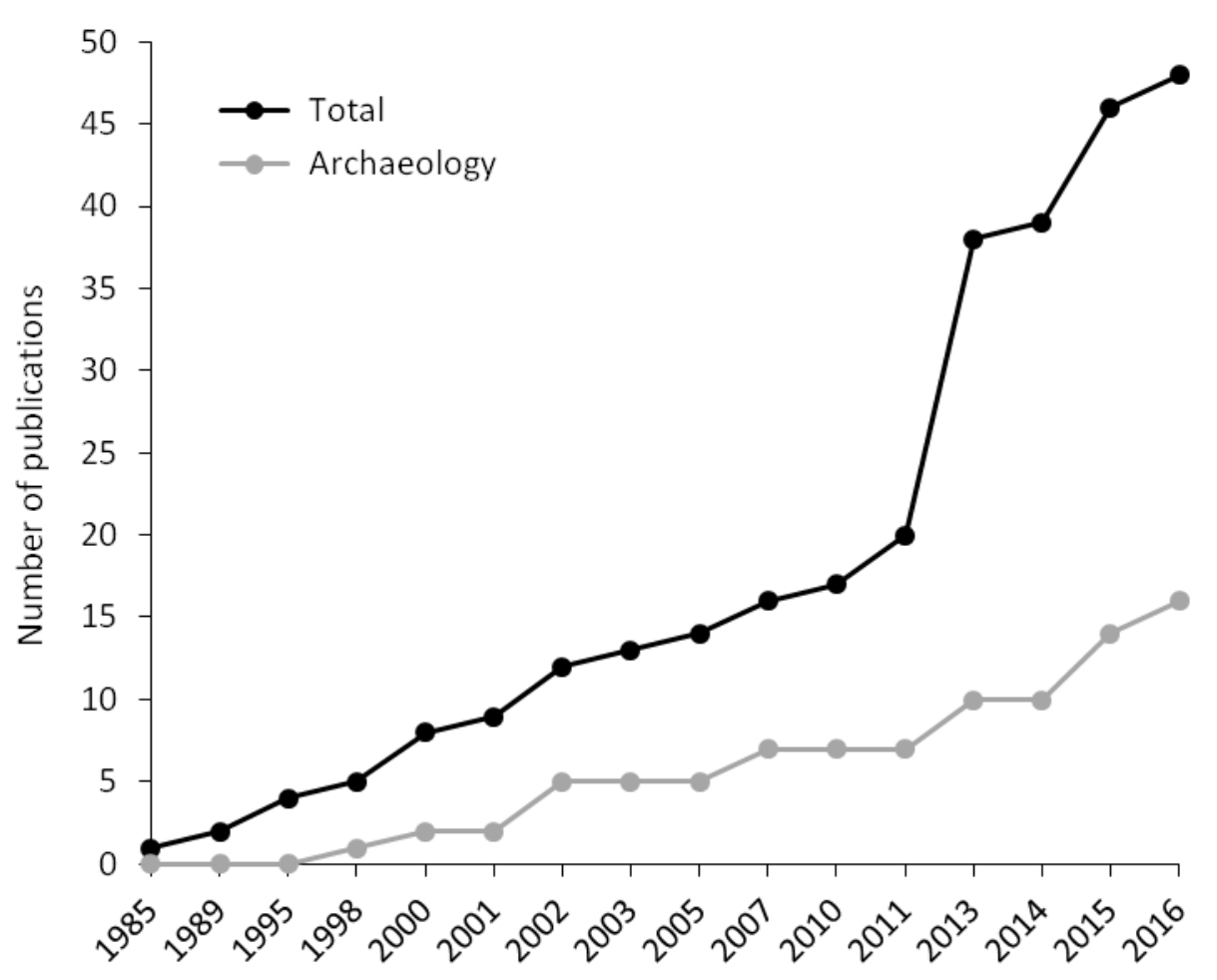

Figure 1: Graph of publications (series "Total") since 1985 that are indexed in Scopus and specifically use SAR for studies of archaeological landscapes, archaeological prospection and condition assessment of cultural heritage. The series "Archaeology" refers to those publications among the "Total" that are co-authored by archaeologists.

Matching evidence is found in Agapiou and Lisandrou (2015) who report that 'radar images' are among the most frequently used terms in the relevant remote sensing literature between 2013 and 2015.

The large percentage of the published research is based on the use of the 'amplitude', i.e. the magnitude of the microwave wavelength recorded for each pixel of the complex SAR image. The 'radar backscatter' as the portion of the outgoing radar signal recorded over successive pulses from elements of a synthetic aperture to create the image, is mostly analysed to infer the compositional and soil moisture properties of the radar targets on the ground and associate them to surface changes that may relate to buried features.

The other main group of publication concentrates on the use of DEMs generated with Interferometric SAR (InSAR) techniques, by which the measured differences in the phase of the return signal between two satellite 
passes is used to combine two radar acquisitions of the same area of the Earth's surface, taken from slightly different angles, to generate accurate height maps (ESA, 2015).

\section{CURRENT OPPORTUNITIES FROM SPACE}

The scientific advancement of satellite radar research for archaeological studies was possible owing to an increasing availability, from the early 1990s, of SAR imagery in the catalogues of the space agencies, covering with more regular frequency not only the Western countries but also remote areas of South America, Asia and Africa. Furthermore, since the early 2000s, the beam modes with which SAR images are acquired have been continuously improved, so that nowadays image analysts, archaeologists and conservation scientists can access data with: wide-swath to spotlight coverage, kilometre to sub-metre spatial resolution, historical and present dates of acquisition, longer to shorter wavelength ( $\mathrm{L} / \mathrm{C} / \mathrm{X}$ bands), monthly to daily revisiting time if collecting time series.

At present radar remote sensing is witnessing the revolutionary turn of the satellites from the first (e.g., ERS1/2, ENVISAT, ALOS, RADARSAT-1/2) to the second generations (e.g., TerraSAR-X, COSMO-SkyMed, Sentinel-1 and ALOS-2). In this context there is a range of opportunities for feature detection, condition and damage assessment (Tapete et al., 2015c, 2016).

\subsection{Space-borne data}

\subsubsection{Legacy SAR archives}

The ERS-1/2 and ENVISAT catalogues of the European Space Agency (ESA) are the most complete and abundant archives of C-band time series, with almost uninterrupted temporal coverage from 1991 to April 2012. Their Image Mode spatial resolution of 25-30 m and swaths of $100 \mathrm{~km}$ make these images suitable for widearea and regional assessments (e.g. detection of paleo-channels, trade route reconstruction), alongside investigation of sites as wholes and contextualised in their surrounding environments (Figure 2a).

Similarly, the archives built by the Japanese Space Agency (JAXA) with the L-band ALOS PALSAR sensor provide an historical view of cultural landscapes from 2006 to May 2011, with resolution up to $7 \mathrm{~m}$ in Fine Beam mode, both single and dual polarised (HH, VV, HH+HV, VV+VH). Kurtcebe et al. (2010) and Guo et al. (2011) are among the earliest studies showcasing the usefulness of ALOS PALSAR in archaeology, while more 
research may be carried out to fully exploit the archives available over those regions in India, South America and Pacific Ocean where ancient civilizations settled and flourished for centuries.

\subsubsection{New satellites and SAR imaging modes}

The TerraSAR-X constellation of the German Aerospace Center (DLR) is a clear example of how on-demand high to very high resolution SAR can nowadays support studies of archaeological landscapes and sites by providing a range of different resolutions, up to unprecedented sub-metre level imaging. Acquiring X-band imagery since mid-2007 with the twin satellite TanDEM-X launched three years later, TerraSAR-X (TSX) is building an image archive with repeat cycle of 11 days (i.e. a third of ESA's first generation sensors) and a range of spatial resolutions, from $16 \mathrm{~m}$ and scene size of $100 \mathrm{~km}$ (width) x $150 \mathrm{~km}$ in ScanSAR mode, to azimuth resolution of 0.24 m over scene extent varying between 2.5 to $2.8 \mathrm{~km}$ in azimuth and 4.6 to $7.5 \mathrm{~km}$ in range in Staring Spotlight mode (Mittermayer et al., 2014).

The Hellenistic town of Apamea, Syria, well demonstrates the paradigm of multi-temporal and multi-scale analysis using different satellites. ScanSAR time series 2011-2014 (Figure 2b) complemented the historical analysis with ERS-1/2 and ENVISAT by providing a regional scale coverage to assess the recent impact on landscape due to the construction of the dam nearby the Justinian walls (see section 3.2.4) and the agricultural activities in the Ghab plain (Figure 2a). Coeval sub-meter resolution Staring Spotlight imagery (Figure 2c; Tapete et al. 2016), instead, allows up-scaling of the observations at the level of individual structures, such as the monumental colonnade of Apamea (Figure 2d). Given the current exposure of the site to war damages, looting and vandalism, the strong backscatter return from the marble columns provides a reliable SAR marker to assess whether the ancient ruins are still standing or collapsed (see section 4.2). 

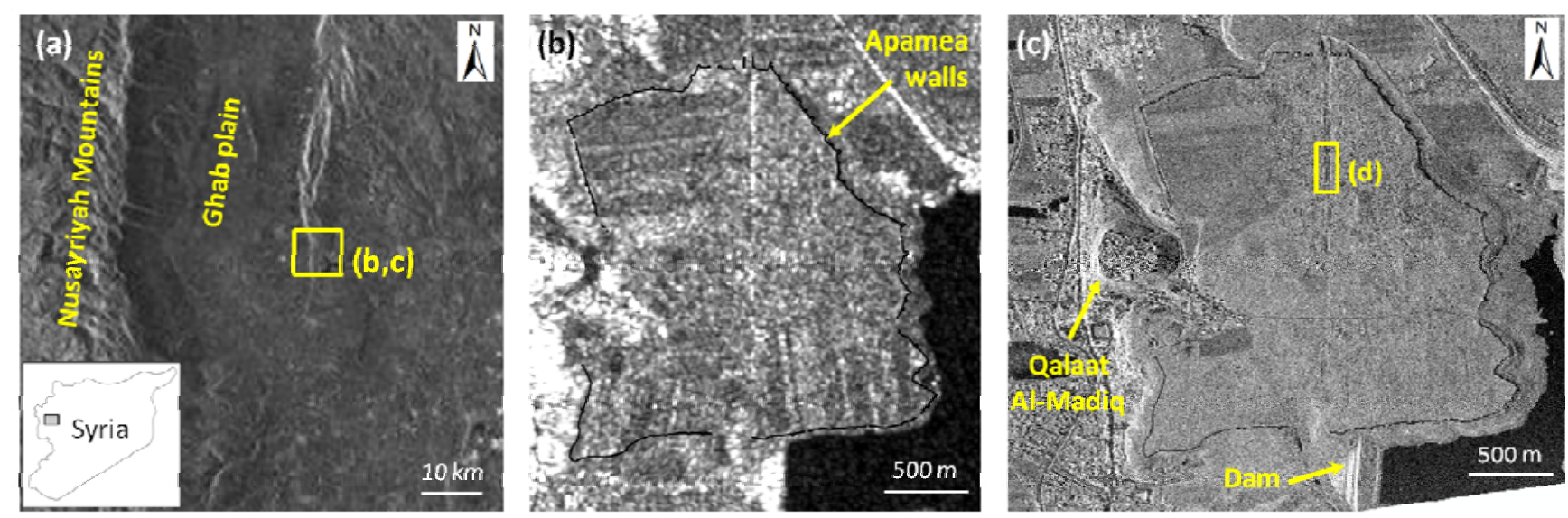

(d)

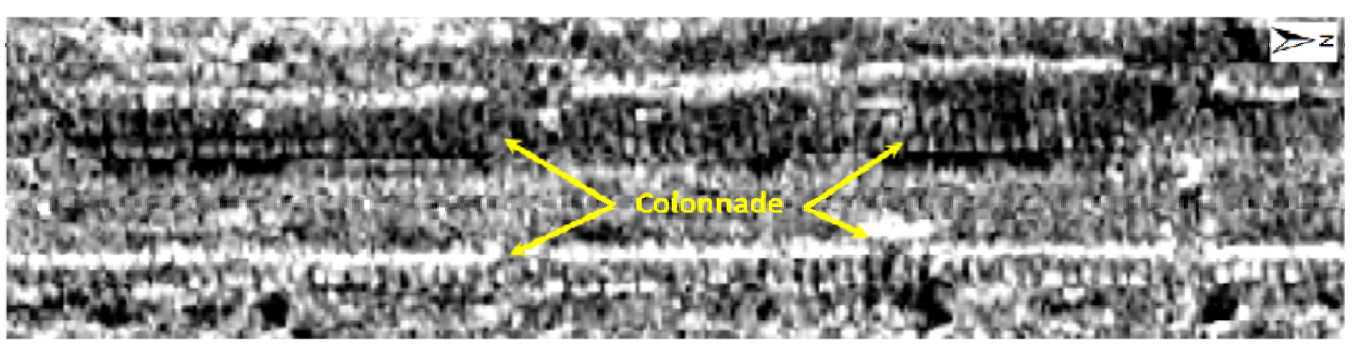

114 Figure 2: SAR opportunities for site investigation. (a) 25-m resolution ENVISAT IS2 VV, 9 June 2006, (b) 17115 m geocoded TerraSAR-X ScanSAR, 17 May 2011 (C DLR 2016), and (c) 0.24-m resolution geocoded Staring 116 Spotlight ascending mode image, 27 December 2014 (C DLR 2016) of Apamea, western Syria. (d) Detail of the 117 monumental colonnade from the Staring Spotlight mode, enhancing the unprecedented very high spatial 118 resolution currently achievable with space-borne SAR. Archaeologists can also benefit from the full range of beam modes and incidence angles offered by the same 121 satellite mission to improve the detection and delineation of subtle archaeological features, whilst relating them to the landscape over a wide swath. Figure 3 demonstrates the stunning improvement in SAR imaging from ScanSAR to High Resolution Spotlight modes to discriminate the UNESCO World Heritage List Nasca Lines, in Southern Peru. The distinctive radar signature of the 'negative geoglyphs' (exposed unpatinated and lighter coloured ground) can be analysed by drawing a backscatter profile from the feature to the nearby soil (dark gravels) and checking its consistency or variations by year or by season (Tapete et al., 2013b). 

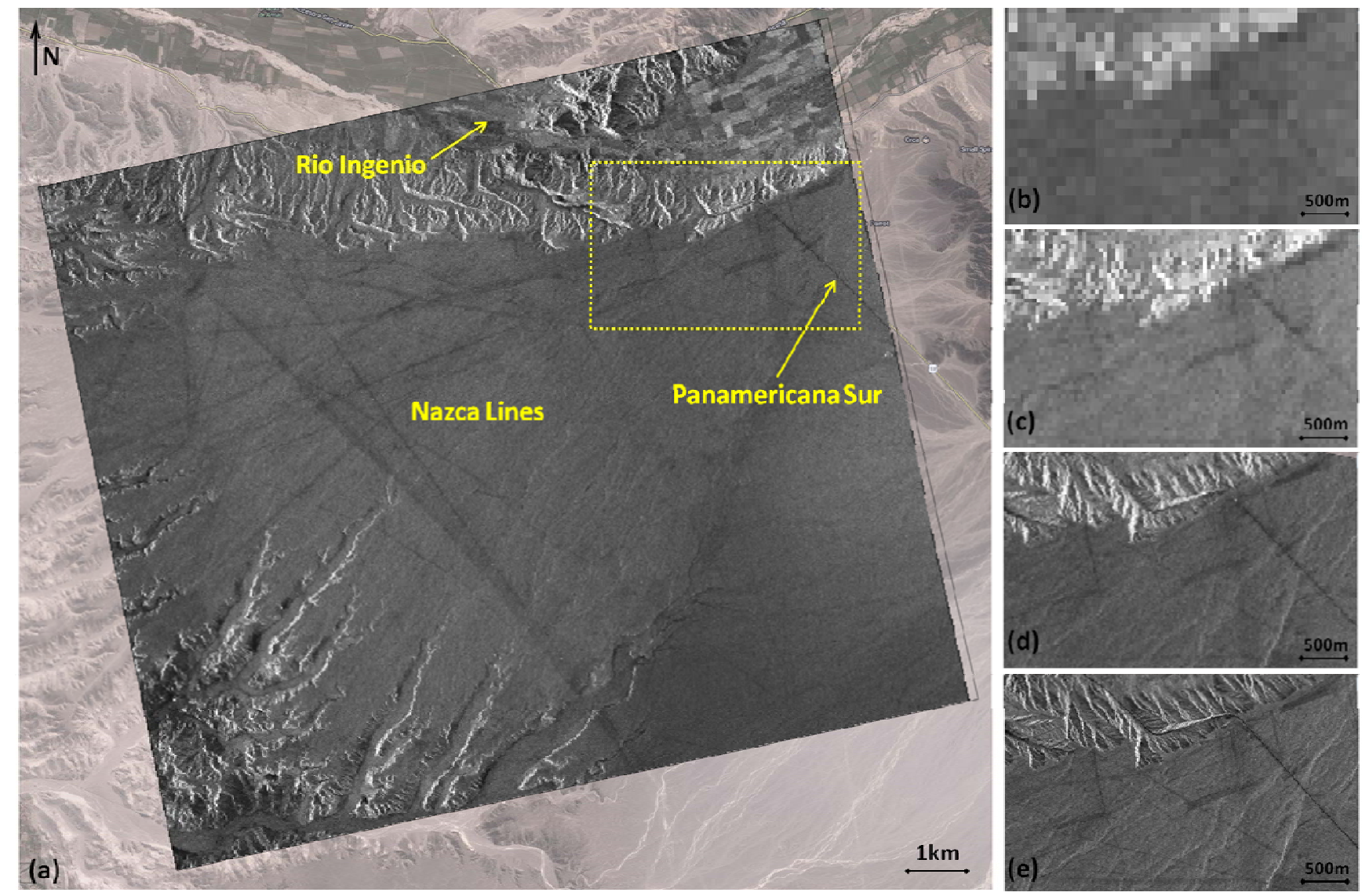

Figure 3: SAR opportunities for feature detection. (a) TerraSAR-X (TSX) SpotLight 13 August 2008 ascending mode with VV polarization, $32.5^{\circ}-33.6^{\circ}$ incidence angles over the Nasca Lines (C DLR 2016), overlapped onto optical imagery (C) 2013 Google Imagery (C Cnes/Spot Image, DigitalGlobe, Map data (C Google). Comparison of: (b) ScanSAR TSX, HH, ascending, range res. 17.0-19.2 m; (c) StripMap TanDEM-X (TDX), HH, ascending, range res. 3.3-3.5 m; (d) SpotLight TSX, HH, descending, range res. 1.7-3.5 m; (e) High Resolution SpotLight TDX, HH, descending, range res. 1.1-3.5 m (C DLR 2016) (modified from Tapete et al., 2015b).

The suitability of SAR remote sensing to the specific purpose of investigating archaeological landscapes relies on the flexibility offered by the radar sensors to tune up the acquisition parameters. In this regard the successor to ALOS PALSAR - namely ALOS-2, launched in May 2014 - can acquire images with single to full polarization, range-azimuth resolution up to $3 \times 1 \mathrm{~m}$ and incidence angles between 8 to 70 degrees in the various

140 beam modes. Operating in L-band, the sensor PALSAR-2 is expected to penetrate more of the topsoil,

141 depending on the incidence angle (see section 3.2.3) at equal environmental conditions (e.g., feature roughness

142 and soil moisture).

143 Conversely, the coeval ESA C-band Sentinel-1A satellite launched in April 2014, with its twin Sentinel-1B 144 launched in April 2016, is building a consistent and regular SAR catalogue with the pre-defined Interferometric 145 Wide swath (IW) mode acquiring data at $5 \mathrm{~m}$ by $20 \mathrm{~m}$ spatial resolution over $250 \mathrm{~km}$ swaths (see the example in 
Figure $4 \mathrm{a}$ in southern Peru), allowing conflict-free high resolution coverage of dual polarisation and interferometric data potentially over all global landmasses (ESA, 2013). The RGB and amplitude change detection analyses presented in Figure 4b-d are exemplars of how the use of regular Sentinel-1 acquisitions allows surface properties (e.g. soil moisture, location and displacement of landforms) to be monitored, and used as a proxy to infer changes due to human activities or natural processes in the landscape. Under a conservation perspective, this is the area where the Sentinel-1 constellation can be valuable for purposes of routine monitoring and condition assessment over wide areas. Emergency observation requests altering the pre-defined Sentinel-1 observation scenario are foreseen, possibly exploiting the 5 x 5 m resolution StripMap (SM) mode over narrow swath width of $80 \mathrm{~km}$ with adjustable beam incidence angle and the elevation beamwidth (ESA, 2013). Section 4.3 illustrates a simulation of the operational capability of Sentinel-1 SM in such a circumstance (Tapete et al., 2015c).

A further element that, undoubtedly, will encourage the use of Sentinel-1 data is their accessibility. The data are free for download and use from the Sentinels Scientific Data Hub (https://scihub.esa.int/), in various formats, i.e. SAR Level-0 (compressed and unfocused SAR raw data), Level-1 (focused data) and Level-2 (geo-located geophysical products). In particular, Level-1 Ground Range Detected (GRD) products are focused SAR data that have been detected, multi-looked and projected to ground range using an Earth ellipsoid model, and provided in GeoTIFF format. These raster images have approximately square resolution pixels and square pixel spacing with reduced speckle, although at the cost of reduced geometric resolution and loss of phase information. Although this means that interferometric analysis is not possible with GRD products, image analysts can use them straightforward with GIS software for purposes of amplitude change detection (see section 3.2.1) or geospatial analysis and data integration. An example of the readiness of these data for use is provided in Figure 4. Sentinel-1A data over the area of the Nasca Civilisation in southern Peru were downloaded from the Sentinels Scientific Data Hub and processed using basic GIS geoprocessing tools to normalise the radar reflectivity of the image pixel as per the Sentinel-1 User Handbook (ESA, 2013) and generate the RGB color composite and the amplitude ratio using the formula reported in section 3.2.1. 

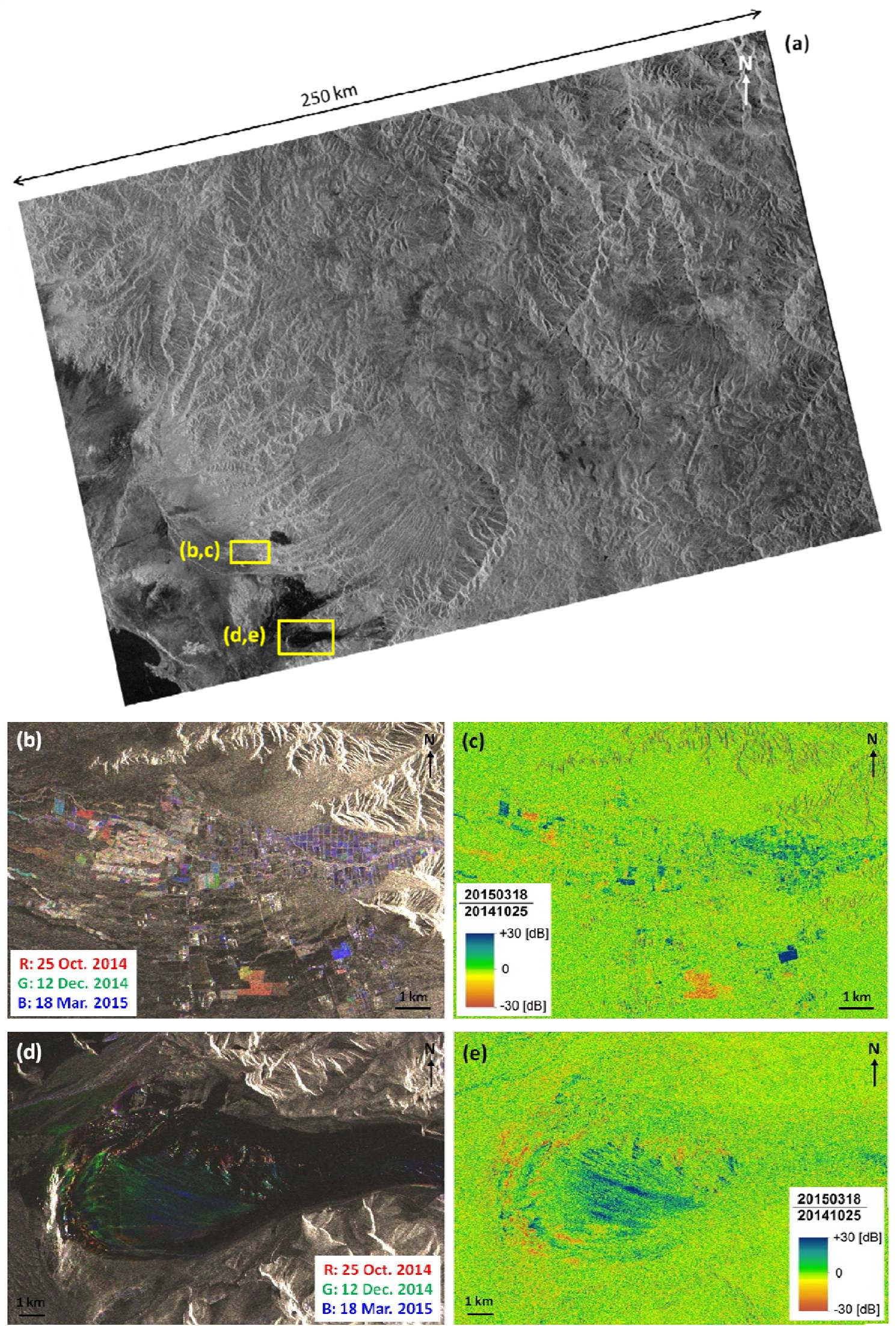

173 Figure 4: (a) Sentinel-1 IW image of the Rio Grande drainage basin in Peru acquired on 25 October 2014 with

174 VV polarisation. (b,d) RGB colour composites and $(c, e)$ image ratios for the area of (b-c) Rio Taruga where soil 175 moisture changes can be recognised in the agricultural fields along the river plain and (d-e) a sand dune where 176 wind-driven mass movements occur. 
178 Nonetheless, whilst the accessibility to Sentinel-1 images has to be recognised as an opportunity for the 179 archaeological community, it is still to determine whether archaeologists already embrace the usefulness of 180 these data, see value for their research purposes and have the necessary skills to use them without the support of 181 image processing analysts. Training and skill development should be part of the process to transfer this 182 technology into the archaeological science practice. In this regard, education initiatives promoted by the image 183 providers are welcome. A recent example is the $3^{\text {rd }}$ course on remote sensing for archaeology organised by ESA 184 and the European Association of Remote Sensing Laboratories - EARSeL (ESA-EARSeL, 2015), with specialist training sessions on the use of SAR data for change detection (Tapete \& Cigna, 2015).

\subsection{Processing methods}

SAR processing methods can be distinguished by the radar parameter used: amplitude and radar backscatter; coherence; polarisation; phase.

\subsubsection{Amplitude change detection}

This method allows the investigation of spatial and temporal changes of the backscattering coefficient $\sigma^{0}$ that indicates the radar signal backscattered to the sensor, normalized - to a first approximation - to the horizontal ground surface and referred to as per unit area on the ground.

Cigna et al. (2013) illustrate the typical workflow to extract, convert to decibel (dB) and analyse values of $\sigma^{0}$ for purposes of change detection. An example of amplitude change detection consists in the computation of ratios between SAR pairs. Two SAR images $k$ and $j$ acquired by using the same acquisition mode and geometry at the times $t_{k}$ and $t_{j}$ respectively are spatially filtered to reduce the effects of radar speckle and increase the signal

$$
R_{\sigma_{i}^{0}}=\frac{\sigma_{i}^{0}\left(t_{k}\right)}{\sigma_{i}^{0}\left(t_{j}\right)}
$$


where $R$ is a dimensionless parameter which takes on values between 0 and 1 when the considered pixel $i$ has higher backscattering coefficient at the time $j$ with respect to time $k$, while values exceeding 1 occur when the pixel $i$ has lower backscattering coefficient at the time $j$ with respect to time $k$.

The result is a map showing the spatial patterns of $\sigma^{0}$ increase and decrease (Figure 5a-b) that offers potential for correlation with changes in soil moisture content, vegetation coverage or morphology, the latter being for instance due to legal or illegal excavations, collapses or demolitions (see section 4.3).

\subsubsection{Multi-temporal coherence}

Coherence $(\gamma)$ is a measure of interferometric phase correlation, and can be computed as the cross-correlation coefficient of two SAR images that is estimated over a small window of a few pixels in range and azimuth, once all the deterministic phase components (mainly due to the terrain elevation) are compensated for (ESA, 2007). Computation of the absolute value of $\gamma$ using a moving window over the whole SAR image results in a coherence map of the observed scene, where values can range from 0 to 1, i.e. from no to perfect correlation. Strong coherence means high homogeneity with no change of land surface properties such as soil moisture, vegetation cover, roughness, elevation or geometry, whilst low $\gamma$ values are found over altered surfaces.

Figure 5 shows how coherence maps can complement an amplitude-based change detection analysis, while

Figure 6 demonstrates the benefit of multi-temporal coherence maps to track changes in the landscape induced by anthropogenic activities (e.g. archaeological excavations) and land surface processes and properties (i.e. soil moisture).

Between 2005 and $2007 R_{\sigma 0}$ patterns were observed in association with loss of coherence in the floodplain of Rio Nazca, Peru, in proximity to Cahuachi, the world largest adobe ceremonial centre (Tapete et al., 2013b). Historically the whole area was affected by flood events to the extent that the settlements were heavily damaged or destroyed (Cigna et al., 2013). Although the river brings fresh mud yearly, thereby creating a fertile strip for agriculture, it still represents a treat for the local archaeological heritage, also due to extreme meteorological events occurring in the mountain range to the east of the plain. Alteration of the radar backscatter between dry, wet and flooded un-vegetated surfaces can be also used to infer the impact in the recent past and assess flood hazard and susceptibility. 

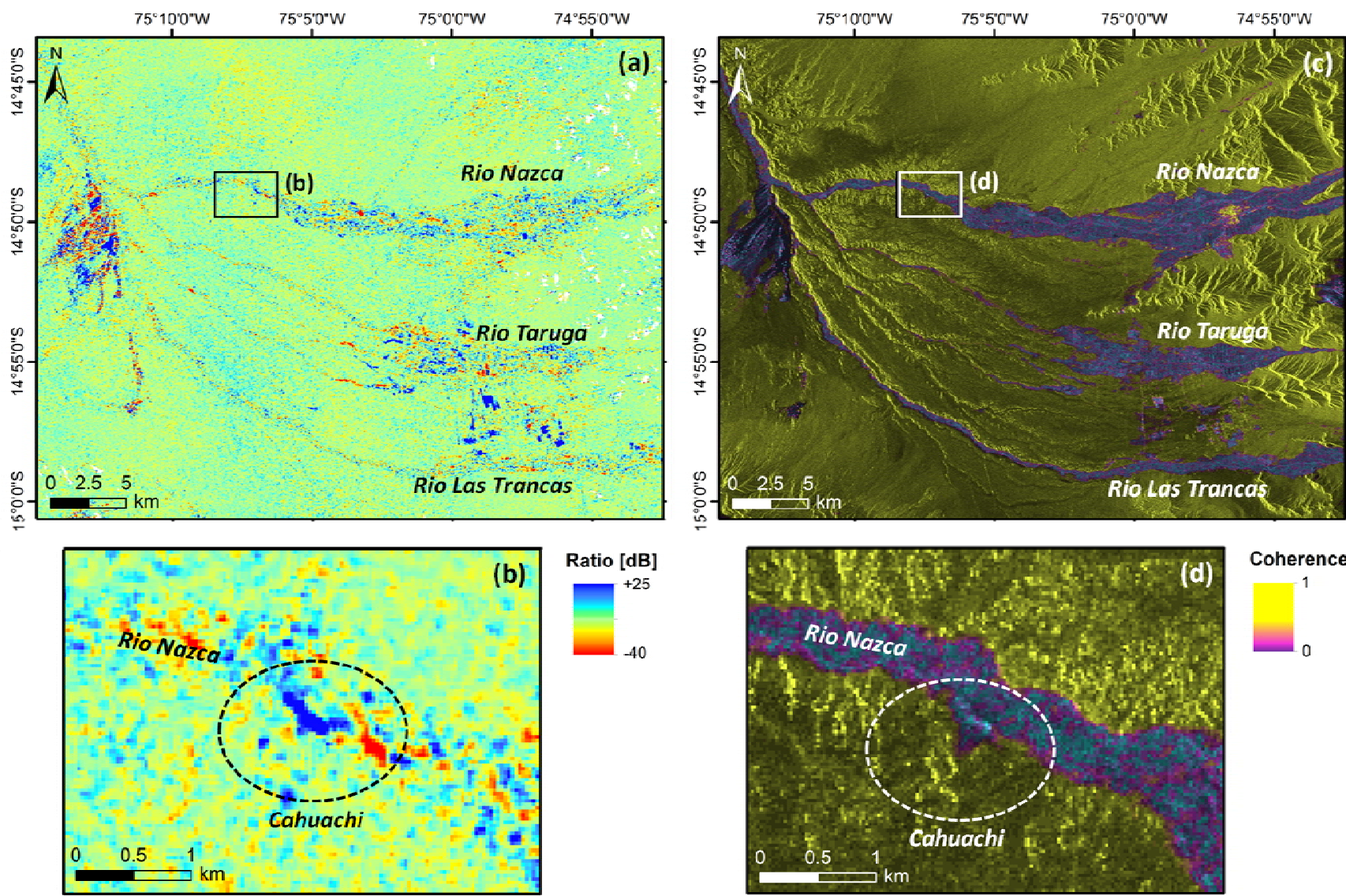

230 Figure 5: Change detection maps based on (a-b) the ratio of the backscattering coefficient between ENVISAT 231 ascending mode images acquired on 2 February 2005 and 7 October 2007, and (c-d) the corresponding 232 coherence maps (perpendicular baseline $4 \mathrm{~m}$ ) over the Nasca Civilisation region in Peru and the archaeological 233 site of Cahuachi. The dotted circles highlight areas where changes in the ratio (blue-red patterns) are associated 234 with loss of coherence (pink-purple patterns) likely due to soil moisture and vegetation changes along the river 235 plain as seen in (a) for the Rio Nazca, Taruga and Las Trancas plains, and archaeological excavations in the area of the ceremonial centre of Cahuachi. 


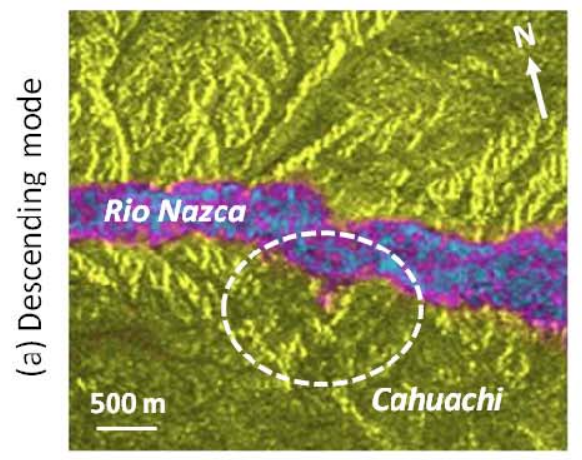

04/02/2003-30/11/2004

$\mathrm{B}_{\text {perp }}=89 \mathrm{~m} ; \mathrm{B}_{\text {temp }}=665$ days

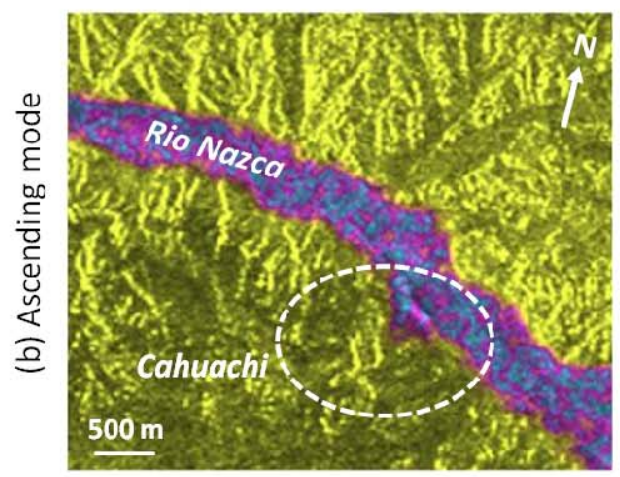

02/10/2005-07/10/2007

$\mathrm{B}_{\text {perp }}=4 \mathrm{~m} ; \quad \mathrm{B}_{\text {temp }}=375$ days

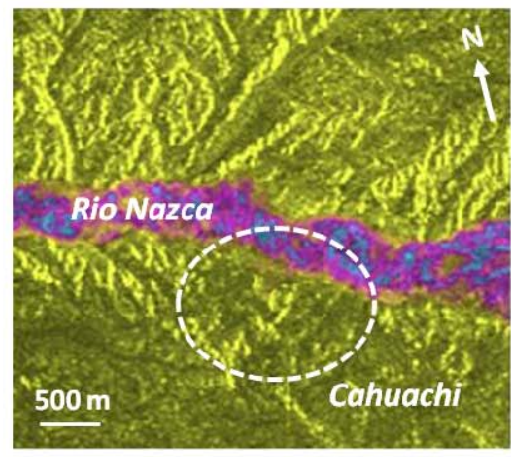

$30 / 11 / 2004-24 / 05 / 2005$

$\mathrm{B}_{\text {perp }}=5 \mathrm{~m} ; \mathrm{B}_{\text {temp }}=175$ days

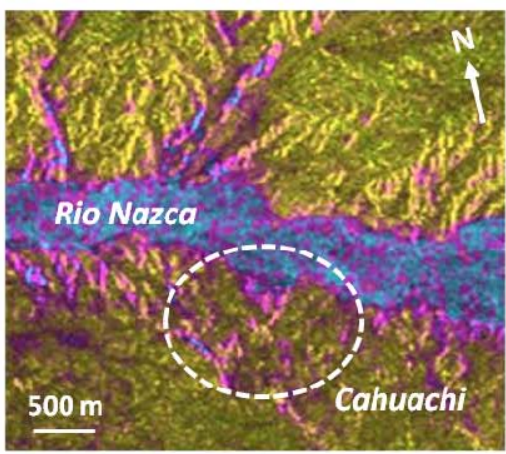

04/02/2003-15/11/2005

$B_{\text {perp }}=343 \mathrm{~m} ; \quad B_{\text {temp }}=1015$ days

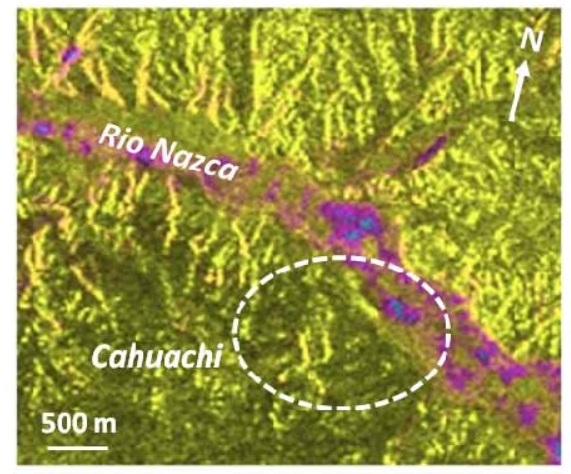

07/10/2007-11/11/2007

$B_{\text {perp }}=180 \mathrm{~m}$; $B_{\text {temp }}=35$ days
InSAR coherence

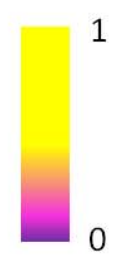

Figure 6: InSAR coherence maps for (a) descending and (b) ascending mode ENVISAT ASAR pairs for the area of Cahuachi in Peru in the period 2003-2007, highlighting decorrelation due to soil moisture changes along the Rio Nazca flood plain, and backscattering variations in the areas of archaeological excavations in the ceremonial centre of Cahuachi. $\mathrm{B}_{\text {temp }}=$ temporal baseline; $\mathrm{B}_{\text {perp }}=$ perpendicular baseline.

\subsubsection{Polarimetric SAR (PolSAR)}

Polarimetry is the measurement and interpretation of the polarization of electromagnetic waves and, for archaeological prospection, is used to detect proxies indicating the existence of buried features. SAR scattering mechanisms of the targets on the ground may differ as a consequence of the type and health of overlying vegetation (Stewart et al., 2014).

249 The typical PolSAR workflow consists of: multi-looking to reduce speckle and obtain a squared pixel (or multi250 temporal averaging in the case of a stack of SAR images); analysis of target decompositions; extraction and 251 analysis the polarimetric signatures to enhance the visibility of suspected buried structures. As demonstrated by Dore et al. (2013) in the sites of Samarra, Iraq, and Djebel Barkal, Sudan, Pauli RGB image of multi-looked polarimetric SAR data is the first qualitative map to identify areas of different polarimetric response, while 
polarimetric descriptors of entropy $(\mathrm{H})$ and alpha angle $(\alpha)$ are obtained by extracting the coherency matrix T3,

to quantitatively analyse the randomness of the scattering mechanism and assess the predominant scattering mechanism between single-bounce, double-bounce or volume scattering. The contribution of these three mechanisms can be then modelled using the Freeman decomposition (Dore et al., 2013), especially when ground-truth measurements are not available.

Patruno et al. (2013) provide an interesting discussion about how different bands, incidence angles and spatial

resolution can be negotiated in a polarimetric analysis to detect subtle to buried features. In the case of Samarra,

although L-band ALOS PALSAR imagery is expected to penetrate more of the topsoil, better results are obtained with the higher resolution C-band RADARSAT-2 full-polarization image acquired with $26.63^{\circ}$ incidence angle to detect the qanät outside the octagonal city. This configuration also proves more suitable than the RADARSAT- 2 image at $43.43^{\circ}$ incidence angle.

Fully polarimetric ALOS PALSAR and RADARSAT-2 images have been also recently used by Gaber et al. $(2013,2015)$ to detect and characterize a well-defined geometric target hidden under sand deposits in the Western Desert of Egypt and classify the surface sediments along El-Gallaba Plain.

These examples further confirm that PolSAR can be very helpful in dry and arid environments, where no interference is caused by soil moisture. Nevertheless, research is needed to assess at what extent PolSAR can support archaeological studies also in temperate zones and exploit the highest resolution SAR beam modes and the flexibility of incidence angle offered by the current space missions.

\subsubsection{DEM generation}

To generate DEMs from radar data, SAR image pairs are acquired by two sensors flying along parallel tracks in across-track formation (not dissimilar to stereo-composition of optical sensors), so as the same point on the ground is imaged simultaneously from two slightly different directions. The typical workflow to generate DEMs with Interferometric SAR processing (InSAR) is fully discussed in ESA (2007).

InSAR DEMs of Earth's surface have been generated since the 1990s, during the Space Shuttle SIR-C/X-SAR missions in 1994 and the 'tandem' mission of ESA's ERS-1 and ERS-2 satellites from 16 August 1995 until mid-May 1996, with ERS-1 and ERS-2 phasing of 1 day (ESA, 2007). In February 2000 the first single-pass radar interferometer in space flew onboard NASA's Shuttle Radar Topography Mission (SRTM; Farr et al., 2007), which generated the first homogeneous, validated and freely available $90 \mathrm{~m}$ resolution global Digital 
Surface Model (DSM) of the Earth. Figure 7a shows the SRTM DSM over the archaeological site of Apamea, 284 Syria, from which the main topographic features and the northern dam are clearly visible.

285 Papers published in Wiseman and El-Baz (2007) report various examples where SRTM was used to extract 286 slope and elevation information in combination with land cover maps and natural resource mapping, to identify 287 anthropogenic settlements, trade routes and migration pathways, alongside prediction of future flood and 288 landslide hazards.

289 The release, since 2014, of the global 1 arc-second $(\sim 30 \mathrm{~m})$ resolution SRTM elevation data will certainly push 290 the landscape research forward, owing to the improved resolution compared to the $90 \mathrm{~m}$ of the previous product 291 that, in recent years, scholars already proved to be valuable for archaeological prospection (e.g. Blom et al., 2922000 for tracking trade routes; Menze et al., 2007 for mapping ancient settlement mounds).

293 In this context, DLR's TanDEM-X mission is revolutionary. In addition to the generation of a worldwide, 294 consistent and high precision global DEM at $12 \mathrm{~m}$ resolution, StripMap (SM) and High Resolution Spotlight 295 (HS) data at 3 and $2 \mathrm{~m}$ resolution are acquired using the operational alternating bistatic and monostatic 296 acquisition modes. A comprehensive quantitative appraisal of the absolute and relative vertical accuracy of 297 these elevation products in an archaeological context was recently published by Erasmi et al. (2014). The 298 authors showed that SM data were suitable to reconstruct a paleo-channel in the alluvial plain of Cilicia, Turkey, 299 and enhanced the micro-topography of fortification towers, gates, theatre and stadium of the ancient city of 300 Magarsos using HS data. 

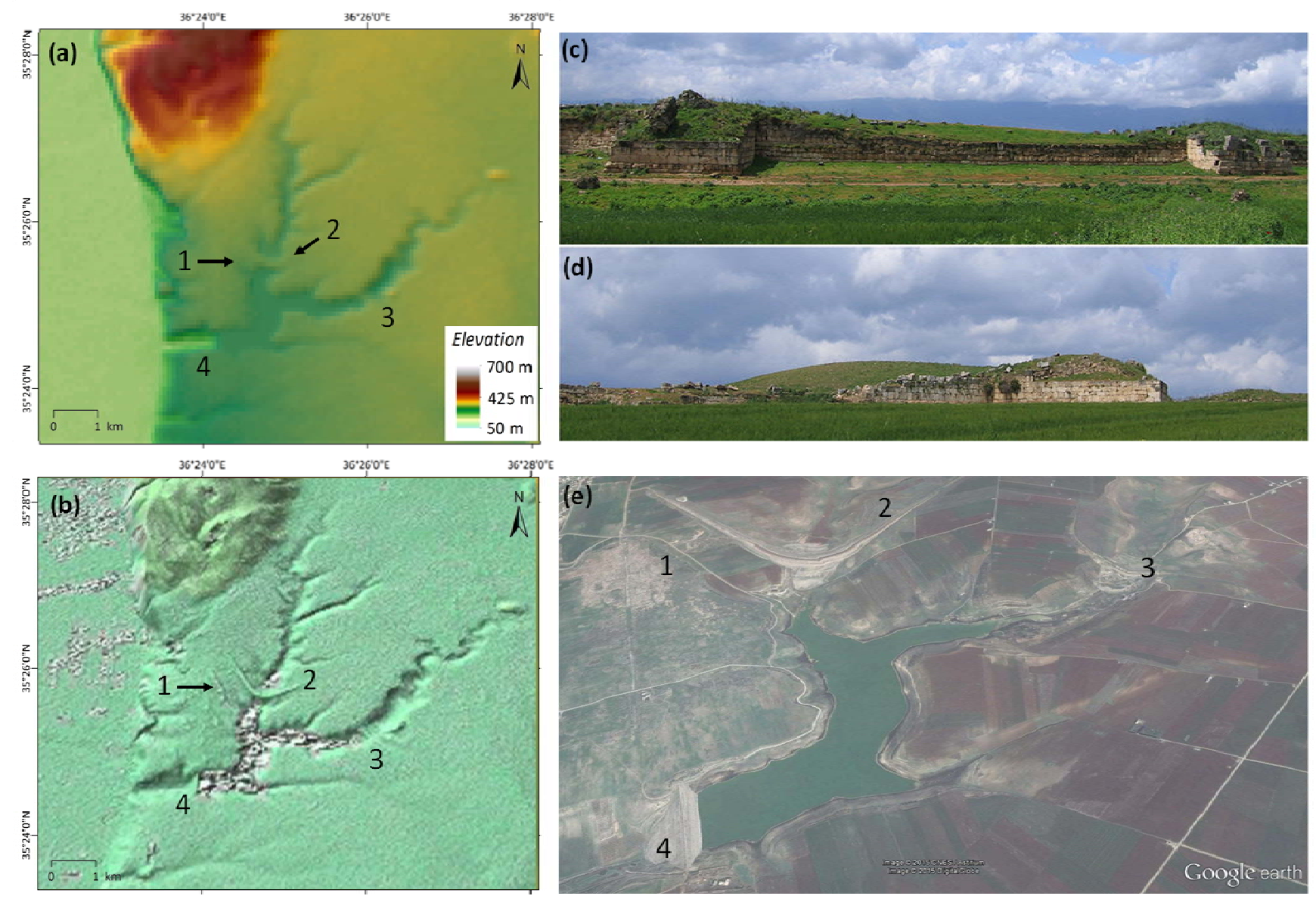

302

Figure 7: (a) 90 m resolution SRTM DSM, (b) shaded relief of 3-m resolution TanDEM-X StripMap Bistatic HH DEM 27 February 2012 (C) DLR 2016) with indication of the archaeological and landscape features of interest for the site of Apamea, Syria (see Figure 2): 1) eastern Justinian walls; 2-4) dams of the Apamea lakes. (c-d) Details of the eastern walls prior to looting; (e) Google Earth image of the Apamea lake and dams (C) 2015 CNES/Astrium; (c) 2015 DigitalGlobe).

Similar results are obtained in Apamea (Figure 7). SM bistatic DEM HH polarization not only improves the delineation of the three dams of the Apamea lake and the topographic features of the natural relief where the ancient town was built, but also allows the recognition of the eastern walls (Figure $7 \mathrm{~b}-\mathrm{d}$ ). This is a clear example of the usefulness of these data to analyse the regional context in which a site can be studied up to the local scale, and anthropogenic impacts on the landscape can be assessed.

Access to high resolution DEMs based on satellite SAR data is an opportunity for archaeological research in those areas across the world where the feasibility of LiDAR data collection from airborne platforms is limited not only due to environmental (cloud-coverage) or funding issues, but also security considerations, such as in sensitive areas or un-accessible regions. 


\section{CULTURAL HERITAGE AND LANDSCAPE APPLICATIONS}

\subsection{Detection of archaeological features}

Given the legacy of historical data and the diverse options for new acquisition with the current space missions (see section 3.1), it would be simplistic and reductive to state that only highest resolution SAR imagery should be used for detection of archaeological features. Images are to be selected accounting for the size, morphology, location and degree of exposure of the features on the ground to investigate.

Tapete et al. (2013b) demonstrated that even medium resolution SAR images such as $30 \mathrm{~m}$ resolution ENVISAT ASAR were suitable to delineate major geoglyphs of Nasca Lines or detect buried and abandoned puquios, although the obvious limitation relates to the precision with which the feature is delimited from the nearby soil and its land use. Furthermore, despite their lower resolution, historical data are sometimes the only imagery available from the space agencies' archives, and can be used to look at past landscapes that have been modified by human actions such as extensive ploughing, dam construction, urban sealing, war damages and vandalism.

At present, except for the L-band ALOS-2 mission, the highest resolution SAR imagery is acquired in Xband (e.g., TerraSAR-X Staring Spotlight and COSMO-SkyMed Spotlight; Figure 2d) which is expected to have lower penetration capability than L-band, at equal environmental conditions. As mentioned in section 3.2.3, a key role is played by the combination of incidence angle, soil properties and surface roughness. An example is presented by Chen et al. (2015a) as part of a review of archaeological marks in SAR imagery. A $1 \mathrm{~m}$ resolution COSMO-SkyMed Spotlight $\mathrm{HH}$ polarization image acquired with $27.32^{\circ}$ incidence angle revealed shallow remains of walls and foundation close to the amphitheatre of Sabratha in Libya.

Figure 8 shows the clear archaeological mark detected over the deserted village of Dar es-Salaam, north of the city of Homs in western Syria, using a 3 m resolution TerraSAR-X StripMap image. The size, shape and location of the amplitude patterns match with the corresponding mark observed in Google Earth, thereby proving that SAR imagery can be an effective alternative to optical data when the latter are not available or cloud-covered. The radar backscatter also enhances the site as a distinctive feature compared with the nearly regular orthogonal agricultural fields in the surroundings, also testifying the extensive program of cadastration or centuriation of the basalt landscape. Dar es-Salaam is nowadays mostly a mass of rubble, with no standing structures. These apparently were demolished over the centuries to source good worked stone for use in the 
local farms. Therefore the spatial investigation of the site extent is crucial to understand the relationship between Dar es-Salaam and the field systems, alongside its physical outreach, i.e. the area of influence and control on the surrounding hinterland.

349
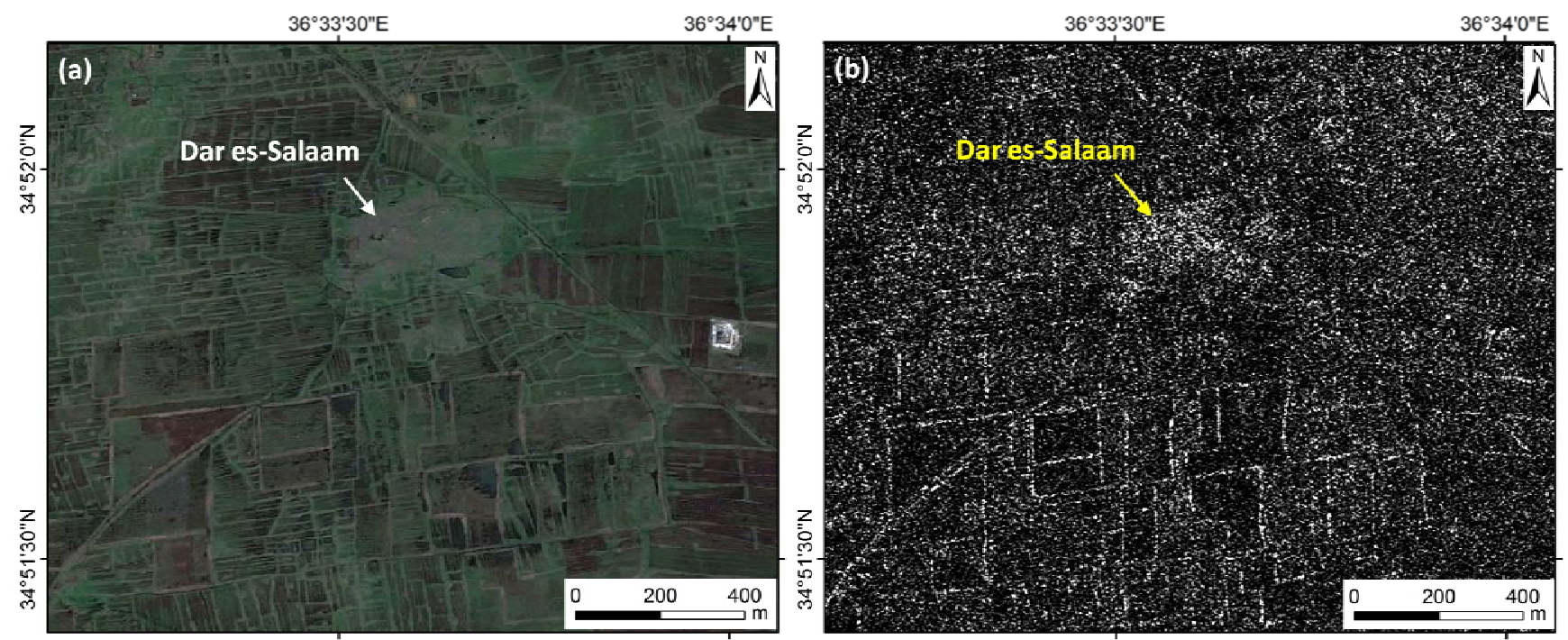

Figure 8: Detection of the archaeological features of the deserted village of Dar es-Salaam, north-west of Homs, Syria. (a) Google Earth image (C DigitalGlobe 2015), (b) TerraSAR-X 3-m resolution StripMap VV image (C DLR 2016) from which the site and surrounding agricultural fields are clearly visible.

\subsection{Condition assessment and environmental monitoring}

There is a wealth of recent literature concerning the use of multi-temporal InSAR for condition assessment of monuments and sites threatened by natural and human-induced hazards (Cigna et al., 2012, 2014; Tapete and Cigna, 2012a,b; Pratesi et al., 2015; Tapete et al., 2012, 2013a, 2015a; Zhou et al., 2015). Multi-temporal InSAR provides sparse grids of point-wise deformation estimates that inform us about the stability of the objects on the ground.

361 On the other side, amplitude change detection techniques (see section 3.2.1) highlight alteration of the landscape and heritage assets in the form of backscatter change patterns (Figure 5b). At a regional scale this can be exploited to investigate the impact of land surface dynamics occurring in a river catchment (Cigna et al., 2013) or as a consequence of extensive cultivation. Geospatial analysis of backscatter changes can suggest a correlation between the distribution and extension of seasonal floodable areas and human settlements (Conesa et al., 2014). At local scale, depending on the spatial resolution of SAR imagery used, it is possible to identify changes due to intentional alteration of archaeological features, such as illegal excavations (Tapete et al., 
2013b). In this regard, the new TerraSAR-X Staring Spotlight mode is opening a new frontier, as it brings, for the first time, SAR data to image looting feature at resolutions comparable with VHR QuickBird, GeoEye and WorldView optical imagery (Tapete et al., 2016).

As mentioned in section 3.2.2, interferometric coherence provides another option to investigate the environmental impact on cultural landscape and features (e.g., Ruescas et al., 2009; Baade and Schmullius, 2010) and is increasingly used in post-disaster damage assessment.

Last but not least, it is worth mentioning that the availability of SAR image stacks can be beneficial to analyse, on a seasonal or yearly basis, geomorphological features relating to past, even vanished or hidden landscapes, such as Quaternary paleo-environments and paleo-shorelines (Bachofer et al., 2014).

\subsection{Damage assessment in areas of conflict}

An area where SAR can complement optical remote sensing is in the assessment of war damages to support the monitoring and protection of cultural heritage in situation of crisis, such as those ongoing in the Middle East and northern Africa. The advantage of operating under any weather conditions and the possibility of acquiring on a regular basis make SAR a gap-filler and an alternative option to using optical or aerial imagery whenever the latter are not feasible.

Figure 9 shows the results of change detection analysis in the city of Homs based on the comparison of $3 \mathrm{~m}$ resolution TerraSAR-X and TanDEM-X VV polarization StripMap acquisitions of August 2009 and December 2014, i.e. prior to and after major impacts of the recent Syrian civil war. Damages and war-related alteration include (a) military blockages and (b) excavations and trenches (Tapete et al., 2015c). Background information and environmental considerations also help to correctly interpret the other change patterns, apparently not due to the conflict such as pre-war demolitions (c) and the flooded area in the top left corner of Figure 9.

As mentioned in section 2.1.2, this is a type of analysis that might be undertaken in emergency contexts using Sentinel-1 StripMap mode over wide areas of investigation, coupled with local-scale assessment based on exploitation of L- and X-band high to very high resolution imagery. 

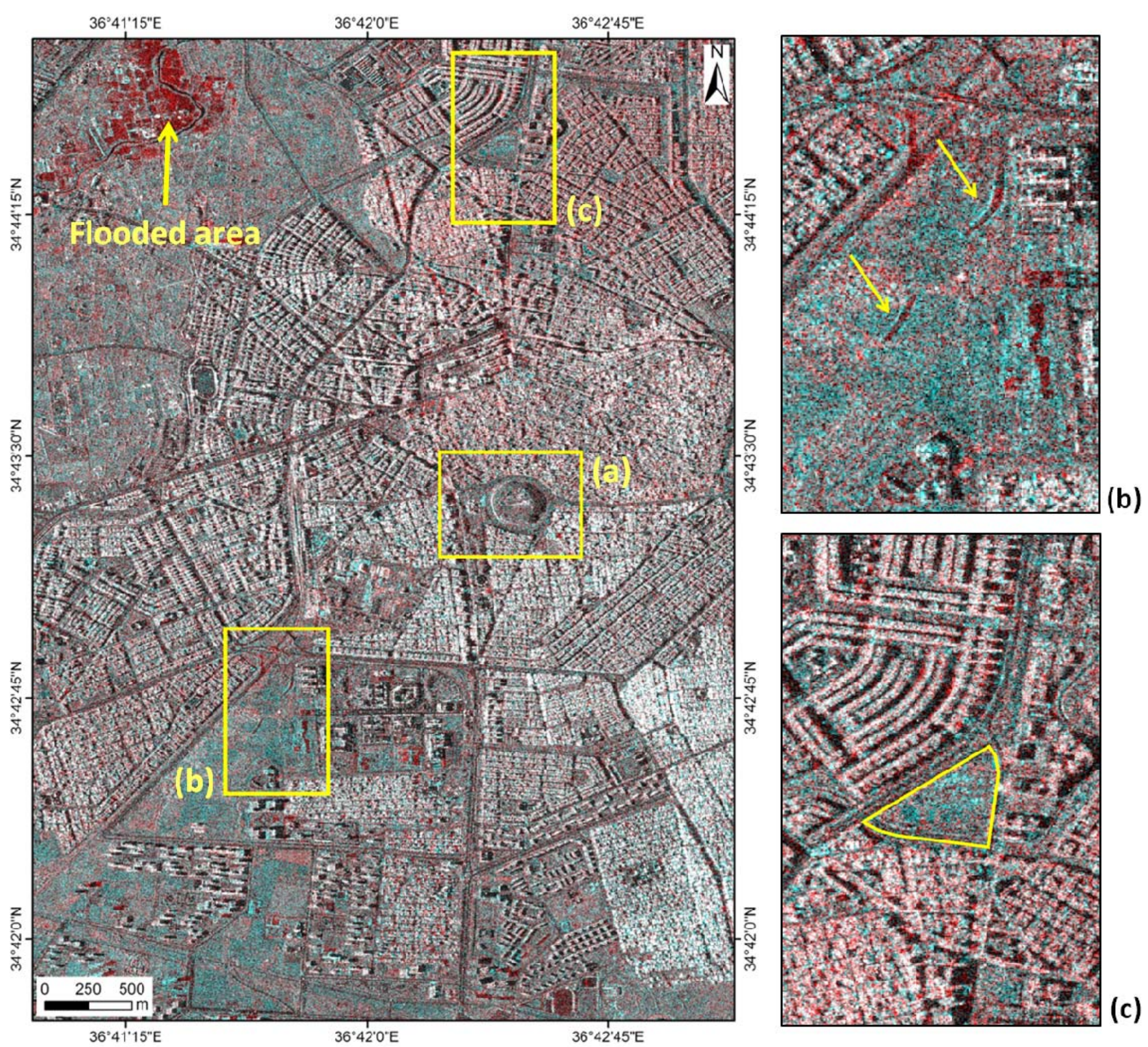

394 Figure 9: RC colour composite of 17 August 2009 and 05 December 2014 VV SM TSX over Homs, Syria (C) 395 DLR 2016), with examples of damages and changes in the urban setting: (a) Homs Tell with evidence of 396 alteration at the bottom of the tell; (b) trenches and embankments in the area of Homs University; (c) Area of 397 pre-war building demolition, northern quarter of Homs (modified from Tapete et al., 2015c).

400 Clear evidence that proves that SAR is now recognised as a valuable technology for investigating archaeology is 401 the increased number of books and dedicated special issues which have been published on this subject in recent 402 years (e.g. Wiseman and El-Baz, 2007; Lasaponara and Masini, 2013). SAR-based heritage studies not only 
involve image analysts, but also archaeologists in a joint effort to improve, if not even develop, SAR image processing techniques to specifically address archaeological questions.

The increased accessibility to SAR data at different spatial resolution and temporal coverage certainly plays a key role in encouraging scientists to undertake tests and pilot studies. But it is the different type of information provided by SAR compared with other Earth Observation techniques - e.g. soil penetration, data to extract topography, nearly regular acquisitions, and visibility in areas where optical sensors do not perform effectively - which likely explains why this technology is increasingly being interrogated by archaeologists, mostly in collaboration with remote sensing experts. The evidence found in the literature is that research outputs coming out from such collaborative projects are increasing, thus suggesting that teamwork between different profiles and professionals is helping to make SAR be more used in archaeology.

As demonstrated in this paper, the type of research currently undertaken with SAR can generate the following scientific, cultural and social impacts:

- retrieval of proxies for surface morphological changes which can inform the decision-making process of local authorities and stakeholders to implement measures to mitigate anthropogenic effects on the cultural been already done in this regard.

Whilst opportunities to access SAR data from space are increasing, training on how to use these data and demonstration of their potential value for archaeological study appear to be practical ways forward to fill the gap between the specialist format of SAR data and the archaeology community, and support the transfer of SAR technology into archaeological practice. 


\section{ACKNOWLEDGEMENTS}

433 TerraSAR-X and TanDEM-X imagery of Syrian sites was provided by the German Aerospace Center (DLR) via 434 the TSX-New-Modes-2013 LAN2377 and TDX XTI-HYDR0399 grants. ENVISAT ASAR data over Apamea 435 (Syria) and the Nasca region (Peru) were provided by ESA via the Cat-1 projects id. 28439 and 11073, 436 respectively. Sentinel-1A data were accessed from ESA's Sentinels Scientific Data Hub. If not otherwise 437 specified, data processing was carried out using GAMMA SAR and Interferometry Software licensed to BGS, 438 NERC. The authors publish with the permission of the Executive Director of BGS, NERC.

\section{REFERENCES}

Adams R, Brown W, Culbert T (1981) Radar Mapping, Archeology, and Ancient Maya Land Use. Science 213:1457-1463

Agapiou, A., Lysandrou, V. (2015) Remote sensing archaeology: Tracking and mapping evolution in European scientific literature from 1999 to 2015. Journal of Archaeological Science: Reports 4: 192-200.

Baade J, Schmullius C (2010) High-resolution mapping of fluvial landform change in arid environments using

Blom, RG, Crippen, RE, Zarins, J, Hedges, GR (2000) Remote sensing, Shuttle Radar Topographic Mapper data, and ancient frankincense trade routes. In: Geoscience and Remote Sensing Symposium, 2000.

Bachofer F, Quénéhervé G, Märker M (2014) The Delineation of Paleo-Shorelines in the Lake Manyara Basin Using TerraSAR-X Data. Remote Sens 6:2195-2212. Proceedings. IGARSS 2000. IEEE 2000 International, Honolulu, HI, 2000, pp. 2477-2479 vol.6.

Chen F, Lasaponara R, Masini N (2015a) An overview of satellite synthetic aperture radar remote sensing in archaeology: From site detection to monitoring. J Cult Herit.

Chen F, Masini N, Yang R et al (2015b) A Space View of Radar Archaeological Marks: First Applications of COSMO-SkyMed X-Band Data. Remote Sens 7:24-50

Cigna F, Del Ventisette C, Gigli G et al (2012) Ground instability in the old town of Agrigento (Italy) depicted by on-site investigations and Persistent Scatterers data. Nat Hazards Earth Syst Sci 12:3589-3603 
Cigna F, Tapete D, Lasaponara R et al (2013) Amplitude change detection with Envisat ASAR to image the cultural landscape of the Nasca region, Peru. Archaeol Prospect 20:117-131

Cigna F, Lasaponara R., Masini N et al (2014) Persistent Scatterer Interferometry Processing of COSMOSkyMed StripMap HIMAGE Time Series to Depict Deformation of the Historic Centre of Rome, Italy. Remote Sens 6:12593-12618

Comer D, Blom R, Golden C, Quilter J, Chapman B (2005) Inventory of Archaeological Sites Using Radar and Multispectral Data. Lecture presented at National Geographic Society, Washington, D.C.

Conesa F, Devanthéry N, Balbo AL et al (2014) Use of satellite SAR for understanding long-term human occupation dynamics in the monsoonal semi-arid plains of North Gujarat, India. Remote Sensing, 6 (11) (2014), pp. 11420-11443.

Dore N, Patruno J, Pottier E et al (2013) New research in polarimetric SAR technique for archaeological purposes using ALOS PALSAR data. Archaeol Prospect 20:79-87

Di Iorio, A., Straccia, N., Carlucci, R (2010) Advancement in automatic monitoring and detection of archaeological sites using a hybrid process of Remote Sensing, GIS Techniques and a Shape Detection Algorithm. Remote Sensing for Science, Education, and Natural and Cultural Heritage. EARSeL, 2010 Accessible at http://www.earsel.org/symposia/2010-symposium-Paris/Proceedings/EARSeL-Symposium$\underline{20102-01 . p d f}$

Elachi C, Roth L, Schaber G (1984) Spaceborne Radar Subsurface Imaging in Hyperarid Regions. IEEE T Geosci Remote 4:383-387

El-Baz F (1998) Prehistoric artifacts near paleo-channels revealed by radar images in the western desert of Egypt. In: Remote Sensing in Archaeology from Spacecraft, Aircraft, on Land, and in the Deep Sea, Boston University, Boston

Erasmi S, Rosenbauer R, Buchbach R et al (2014) Evaluating the Quality and Accuracy of TanDEM-X Digital Elevation Models at Archaeological Sites in the Cilician Plain, Turkey. Remote Sens 6:9475-9493

ESA (2007) TM-19 InSAR Principles: Guidelines for SAR Interferometry Processing and Interpretation. Part B InSAR processing: a practical approach. TM-19_ptB http://www.esa.int/esapub/tm/tm19/TM-19_ptB.pdf

ESA (2013) ESA Sentinel-1 User Handbook. ESA Standard Document, GMES-S1OP-EOPG-TN-13-0001. 1 September 2013, 80 pp. https://sentinel.esa.int/ 
Guide.

Glossary.

https://sentinel.esa.int/web/sentinel/sentinel-1-sar-wiki/-/wiki/Sentinel\%20One/Glossary

ESA-EARSeL (2015) 3rd ESA-EARSeL course on remote sensing for archaeology - Training, European Space Agency. Accessible at http://earth.esa.int/heritage/2015-events/15m38/training.html

Evans, D, Pottier, C, Fletcher, R., Hensley, S., Tapley, I., Milne, A., Barbetti, M. (2007) A comprehensive archaeological map of the world's largest preindustrial settlement complex at Angkor, Cambodia.

Farr TG, Rosen PA, Caro E et al (2007) The Shuttle Radar Topography Mission. Rev Geophys 45, RG2004/2007. doi:10.1029/2005RG000183

Gaber A, Koch M, Griesh MH et al (2013) Near-surface imaging of a buried foundation in the Western Desert, Egypt, using space-borne and ground penetrating radar. J Archaeol Sci 40: 1946-1955

Gaber A, Soliman F, Koch M et al (2015) Using full-polarimetric SAR data to characterize the surface sediments in desert areas: A case study in El-Gallaba Plain, Egypt. Remote Sens Environ 16:11-28

Guo, Huadong; Li, XinWu; Liu, Guang; Zhang, Lu; Zhu, LanWei; Yang, Huaining; Yan, Shiyong; Ruan, Zhixin (2011) Study For Land SurfaCe Properties With Alos Palsar. Accessible at https://repository.exst.jaxa.jp/dspace/bitstream/a-is/16537/1/65135024.pdf

Lasaponara R, Masini N (2013) Satellite synthetic aperture radar in archaeology and cultural landscape: An overview. Archaeol Prospect 20:71-78

Lira, J, Lopez, P., Rodriguez, A. (2005) Detection of Maya's archaeological sites using high resolution radar images. International Journal of Remote Sensing 26(6): 1245-1260.

Kurtcebe, F, Pfeifer, N, Ipbuker, C (2010) Remotely sensed archeology: Recent applications with DAICHI (Conference Paper). In: 31st Asian Conference on Remote Sensing 2010, ACRS 2010; Hanoi; Viet Nam; Volume 2, 2010, pp. 1168-1175.

Menze, BH, Ur, JA, Sherratt, AG (2006) Detection of Ancient Settlement Mounds: Archaeological Survey Based on the SRTM Terrain Model. Photogrammetric Engineering \& Remote Sensing 72(3): 321-327.

Mittermayer J, Wollstadt S, Prats-Iraola P et al (2014). The TerraSAR-X Staring Spotlight Mode Concept. IEEE T Geosci Remote 52:3695-3706

Moore E, Freeman T, Hensley S (2007) Spaceborne and Airborne Radar at Angkor: Introducing New technology to the Ancient Site. In: J.R.Wiseman \& F. El-Baz (eds) Remote Sensing in Archaeology, 
technology to the Ancient Site. In: J.R.Wiseman \& F. El-Baz (eds) Remote Sensing in Archaeology, Springer, pp. 185-218.

Patruno J, Dore N, Crespi M et al (2013) Polarimetric multifrequency and multi-incidence SAR sensors analysis for archaeological purposes. Archaeol Prospect 20:89-96

Pratesi F, Tapete D, Terenzi G et al (2015) Rating health and stability of engineering structures via classification indexes of InSAR Persistent Scatterers Int J Appl Earth Obs 40:81-90

Ruescas AB, Delgado JM, Costantini F et al (2009) Change detection by interferometric coherence in Nasca Lines, Peru (1997-2004). In: Fringe Workshop Proceedings 2009, European Space Agency SP-677, ESAESRIN, Frascati, 30 November- 4 December 2009

Stewart C, Lasaponara R, Schiavon G (2014) Multi-frequency, polarimetric SAR analysis for archaeological prospection. Int J Appl Earth Obs 28:211-219

Tapete D, Cigna F (2012a) Rapid mapping and deformation analysis over cultural heritage and rural sites based on Persistent Scatterer Interferometry. Int J Geophys. doi:10.1155/2012/618609

Tapete D, Cigna F (2012b) Site-specific analysis of deformation patterns on archaeological heritage by satellite radar interferometry. In: 20th International Materials Research Congress, Symposium 8 Cultural Heritage and Archaeological Issues in Materials Science, MRS Proceedings 1374, Cambridge University Press, p 283-295

Tapete, D., Cigna, F. (2015) Change detection in cultural landscapes. In: 3rd ESA-EARSeL course on remote sensing for archaeology - Training, European Space Agency. Accessible at http://earth.esa.int/heritage/2015events/15m38/Training/14_Tapete_Cigna.pdf

Tapete D, Cigna F, Donoghue D.N.M. (2016) 'Looting marks' in space-borne SAR imagery: Measuring rates of archaeological looting in Apamea (Syria) with TerraSAR-X Staring Spotlight. Remote Sensing of Environment 178: 42-58.

Tapete D, Fanti R, Cecchi R et al (2012) Satellite radar interferometry for monitoring and early-stage warning of structural instability in archaeological sites. J Geophys Eng 9:S10-S25

Tapete D, Casagli N, Luzi G et al (2013a) Integrating radar and laser-based remote sensing techniques for monitoring structural deformation of archaeological monuments. J Archaeol Sci 40:176-189

Tapete D, Cigna F, Masini N et al (2013b) Prospection and Monitoring of the Archaeological Heritage of Nasca, Peru, with ENVISAT ASAR. Archaeol Prospect 20:133-147 
543 Tapete D, Morelli S, Fanti R et al (2015a) Localising deformation along the elevation of linear structures: An 544 experiment with space-borne InSAR and RTK GPS on the Roman Aqueducts in Rome, Italy. Appl Geogr $545 \quad 58: 65-83$

546 Tapete D, Cigna F, Lasaponara R et al (2015b) Multi-scale detection of changing cultural landscapes in Nasca 547 (Peru) through ENVISAT ASAR and TerraSAR-X. In: Lollino G et al (eds), Engineering Geology for $548 \quad$ Society and Territory - Volume 8, Springer International Publishing, p 339-343

549 Tapete D, Cigna F, Donoghue DNM et al (2015c) Mapping changes and damages in areas of conflict: from 550 archive C-band data to new HR X-band imagery, towards the Sentinels. In: Proceedings of FRINGE'15: 551 Advances in the Science and Applications of SAR Interferometry and Sentinel-1 InSAR Workshop, Frascati, 552 Italy, 23-27 March 2015, Ouwehand L., Ed., ESA Publication SP-731. doi:10.5270/Fringe2015.149

553 Wiseman J, El-Baz F (eds) (2007) Remote Sensing in Archaeology. Springer, New York

554 Zhou W, Chen F, Guo H (2015) Differential radar interferometry for structural and ground deformation 555 monitoring: a new tool for the conservation and sustainability of cultural heritage sites. Sustainability $556 \quad 7: 1712-1729$ 